\title{
Latest Application Technology in Wheat Crop Simulation and Disease Prediction Models
}

\author{
Ioannis Vagelas*
}

Assistant Professor, Department of Agriculture Crop Production and Rural Environment, University of Thessaly, Greece

ISSN: 2637-7659

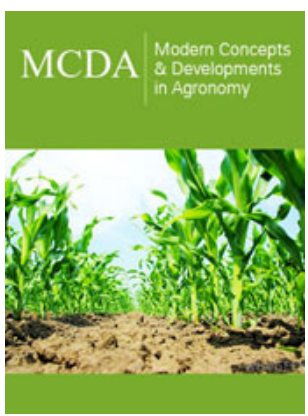

*Corresponding author: Ioannis Vagelas,Assistant Professor, Department of Agriculture Crop Production and Rural Environment, University of Thessaly, Fytokou St., N. Ionia, GR38446 Magnesia, Greece

Submission: 酬 December 08, 2020

Published: 㘹January 25, 2021

Volume 7 - Issue 5

How to cite this article: Ioannis Vagelas. Latest Application Technology in Wheat Crop Simulation and Disease Prediction Models. Mod Concep Dev Agrono. 7(5). MCDA. 000674. 2021. DOI: 10.31031/MCDA.2021.07.000674

Copyright@ Ioannis Vagelas, This article is distributed under the terms of the Creative Commons Attribution 4.0 International License, which permits unrestricted use and redistribution provided that the original author and source are credited.

\section{Abstract}

This short review presents briefly both the history and the present state of crop and disease forecast models. This review discuss both models views and presents our experience about Leaf Blotch Diseases of Wheat.

Keywords: Crop models; Disease forecasting models of agricultural crop; Wheat

\section{Historical review}

Crop models have proved a key tool in assessing crop growth and development and have been influenced by crop management and environmental conditions. Crop simulation models have a long history, started as farm optimization models in 1950-60s and established in 1960s as new methods for agricultural production. In 1970s, crop models supported many advancing cropping and other biological systems and they began appearing on personal PCs in the early 1980s and connect computers globally in 1980 through early 1990s as software package suites, comprises crop simulation models such as the CERES Models for maize and wheat, APISIM, DSSAT and others [1]. In our days the DSSAT (Decision-Support System for Agro-technology Transfer) is a crop simulation model for over 42 crops. DSSAT models simulate growth, development and yield of crops as a function of the soil-plant-atmospheremanagement dynamics. DSSAT require as inputs, daily weather data, soil surface and profile information, detailed crop management and crop genetic information (https//dssat.net).

In general crop models are mathematical algorithms that can simulate information of ecophysiology and agronomy in a way to predict crop growth and development. As crop production is affected seasonal and climatic change needs to combine in their framework the complexity of temperature, rainfall patters and the occurrence of abiotic and biotic stresses. Many authors have evaluated these aspects in wheat crop models for example Ceres-Wheat, Nwheat, CROPSIM-Wheat and APSIM-Wheat to describe performance of early, optimum and late sown wheat associated with temperatures [2]. Many other models were used as wheat simulation models e.g. DSSAT-CERES-Wheat, DSSAT-Nwheat, Wheat Grow and APSIM Wheat, to quantify and simulate the responses of wheat grain quality under critical growth stages [3] or were used to understanding wheat yield reduction under extreme weather [4].

Besides crop model's emphasis was given to disease forecasting models such as i) the model for late blight of potato (Phytophthota infestans) started in 1990s and ii) the model for early blight (Alternaria solani) started in 1999. Both were biological forecasting models, emphasize the weather conditions that favor disease development and related to the complete life cycle of the fungus. PLANT-Plus is recognized as the most successful forecasting model applicable to potato fields as a decision support system to reduce the number of fungicides applications without negatively affecting yield or return [5].

\section{Our Experience from Greece}

For foliar diseases of wheat: Leaf rust, Powdery mildew, Septoria tritici blotch and Tan spot many authors used models containing both abiotic and biotic factors. Abiotic factors: temperature, relative humidity, total rainfall, are using in a wheat growing season as predictor variables for the model in order 
i. to find the most predominant pathogen,

ii. for disease scoring and

iii. for fungicide timing.

In our view, for the wheat crop the third outcome (fungicide timing) is a more complex part of the model combining data for,

i. the upper crop canopy area (leaf layer),

ii. the timing of disease development and

iii. the efficacy of fungicide treatment. In our view, those aspects are important for making fungicide decisions during the growing season.

Moreover, we believe that wheat disease forecasting models need to understand better the foliar fungal pathosystem, for example in Septoria leaf blotch upward dispersal, a predictive model need to be identified in depth the

i) spatial density of plant organs

ii) pathogen infection and phase of latency period and

iii) the last fungal infection cycle and the numerous generations during the crop growing season.

Emphasize to Leaf Blotch Diseases of Wheat (Septoria tritici blotch, Stagonospora nodorum blotch and Tan spot), models should estimate the fungus biomass based to primary inoculum and parameterized the delivered data e.g. data derived from the DSSAT-
CERES-Wheat with the disease data, including parameters for the host (crop), environmental factors and the biology of the pathogen.

Based to climate change we believe that crop disease modeling has a crucial role to play in enabling high yields to crops such as wheat ensuring food security in the future. We believe that climate change impacts will differ between crops, diseases and geographic locations. Crop models and disease forecasting models should highlight these aspects and develop a more accurate process of gathering and measuring information on crop variables and against crop diseases.

\section{References}

1. Jones JW, Antle JM, Basso B, Boote Kenneth J, Conant RT, et al. (2017) Brief history of agricultural systems modeling. Agricultural Systems 155: 240-254.

2. Hussain J, Khaliq T, Ahmad A, Akhtar J (2018) Performance of four crop model for simulations of wheat phenology, leaf growth, biomass and yield across planting dates. PloS one 13(6): e0197546.

3. Osman R, Zhu Y, Ma W, Zhang D, Ding Z, et al. (2020) Comparison of wheat simulation models for impacts of extreme temperature stress on grain quality. Agricultural and Forest Meteorology pp. 288-289.

4. Shew AM, Tack JB, Nalley LL, Chaminuka P (2020) Yield reduction under climate warming varies among wheat cultivars in South Africa. Nature Communications 11(1): 4408.

5. van der Waals JE, Denner FDN, van Rij N, Korsten L (2003) Evaluation of PLANT-Plus, a decision support system for control of early blight on potatoes in South Africa. Crop Protection 22(6): 821-828. 